(2) Open Access Full Text Article

\title{
Ferroptosis-Related APOE, BCL3 and ALOX5AP Gene Polymorphisms are Associated with the Risk of Thyroid Cancer
}

\author{
Zhifu Xiao',*, Haixia Zhao ${ }^{2, *}$ \\ 'Department of Thyroid Surgery, Shanxi Provincial People's Hospital, Taiyuan, Shanxi, 030012, People's Republic of China; ${ }^{2}$ Central Lab, General \\ Hospital of Taiyuan Iron and Steel Group, Taiyuan, Shanxi, 030003, People's Republic of China \\ *These authors contributed equally to this work \\ Correspondence: Zhifu Xiao, Department of Thyroid Surgery, Shanxi Provincial People's Hospital, 29 Shuangtasi Road, Taiyuan, Shanxi, 0300I2, \\ People's Republic of China, Tel/Fax +86 035I-4960327, Email wangxiaozhifu@I26.com
}

\begin{abstract}
Purpose: This study aimed to evaluate the association between polymorphisms in the ferroptosis-related genes apolipoprotein $\mathrm{E}(A P O E)$, BCL3 transcription coactivator $(B C L 3)$ and arachidonate 5-lipoxygenase activating protein $(A L O X 5 A P)$ and the risk of thyroid cancer.

Methods: Six single nucleotide polymorphisms (SNPs) of APOE (rs429358 and rs7412), BCL3 (rs34698726 and rs8100239) and ALOX5AP (rs4076128 and rs4073259) were genotyped in 520 papillary thyroid carcinoma cases and 520 healthy controls using the MassARRAY platform.

Results: The rs429358-TC, rs34698726-TA/TT, and rs8100239-AT/AA genotypes exhibited an elevated risk of thyroid cancer $\left(p_{\mathrm{rs} 429358}=0.002, p_{\mathrm{rs} 34698726}=0.007, p_{\mathrm{rs} 8100239}=0.002\right)$, while rs7412-CT/TT and rs4076128-GA/GG were found to be protective genotypes against the risk of disease $\left(p_{\mathrm{rs} 7412}=0.0003, p_{\mathrm{rs} 4076128}=0.0001\right)$. Genetic model analysis showed that $A P O E$-rs429358 was correlated with an increased risk of disease under dominant and log-additive models $\left(p_{\text {dominant }}=0.0004, p_{\text {log-additive }}=0.0006\right)$. BCL3s34698726 and rs8100239 were associated with an elevated risk of disease under all three genetic models $(p<0.05)$. In contrast, $A P O E$-rs7412 was related to a decreased risk of thyroid cancer under dominant and log-additive models $\left(p_{\text {dominant }}=0.0001, p_{\text {log-additive }}\right.$ $=0.0001)$. Moreover, $A L O X 5 A P$-rs4076128 was also correlated with a reduced risk of disease under all three genetic models $(p<$ $0.05)$.
\end{abstract}

Conclusion: The results help us better understand how genetic polymorphisms in ferroptosis-related genes are relevant to thyroid cancer susceptibility.

Keywords: thyroid cancer, single nucleotide polymorphisms, SNPs, APOE, BCL3, ALOX5AP

\section{Introduction}

Thyroid cancer is the most common endocrine system malignant tumor, ranking as the ninth most commonly diagnosed cancer in the world. ${ }^{1}$ The incidence of the disease is related to region, race, and sex, and the incidence in women is two to four times higher than that in men. ${ }^{2}$ There are four pathological types: papillary carcinoma, follicular carcinoma, undifferentiated carcinoma and medullary carcinoma. ${ }^{3}$ Papillary carcinoma is the most common type of thyroid cancer, with low malignancy and good prognosis. ${ }^{4}$ Ionizing radiation has been identified as a direct risk factor for thyroid cancer, ${ }^{5}$ and obesity, smoking, hormonal exposure and environmental pollutants have also been considered risk factors for the disease. ${ }^{6}$ Genetic factors have important functions in the onset of thyroid cancer, and previous studies have reported many variants associated with the disease..$^{7-9}$ However, to date, the etiology of thyroid cancer is still not well elucidated, and novel targets for the early diagnosis and treatment of the disease are urgently needed. 
Ferroptosis refers to programmed cell death characterized by iron ion-dependent lipid reactive oxygen production and peroxidative damage of cell membrane lipids. ${ }^{10}$ In recent years, an increasing number of studies have revealed that ferroptosis is closely associated with the onset and development of cancer and have brought new possibilities for cancer therapeutics. ${ }^{11}$ A recent study identified several ferroptosis-related genes that may influence the immune infiltration and progression of thyroid cancer, including apolipoprotein E ( $A P O E)$, BCL3 transcription coactivator (BCL3), and arachidonate 5-lipoxygenase activating protein $(A L O X 5 A P) .{ }^{12} \mathrm{APOE}$ is an important apoprotein that binds to peripheral cell receptors and is essential for the catabolism of triglyceride-rich lipoprotein constituents. Abnormal expression of $A P O E$ has been involved in the tumorigenesis of several cancers, such as melanoma and breast and colorectal cancer. ${ }^{13-15} B C L 3$ is a proto-oncogene that functions as a transcriptional coactivator that is activated through its association with NF-kappa B homodimers. ${ }^{16} B C L 3$ is deregulated in many cancers, including breast, colorectal, and prostate cancers. ${ }^{17-19}$ ALOX5AP localizes to the plasma membrane and is involved in the transport and activation of 5-lipoxygenase. ALOX5AP has been widely investigated in various types of inflammatory responses and cancers. ${ }^{20}$ However, little information is available about the single nucleotide polymorphisms (SNPs) of $A P O E, B C L 3$ and $A L O X 5 A P$ in thyroid cancer.

In this study, we selected six SNPs in $A P O E, B C L 3$ and $A L O X 5 A P$ based on previous association studies. $A P O E$ rs429358 has been associated with breast cancer, myocardial infarction and gallbladder disease. ${ }^{21,22} A P O E$-rs 7412 is correlated with the risk of T2DM in Egyptians. ${ }^{23}$ Rs34698726 and rs8100239 in BCL3 are associated with the risk of breast cancer and survival of lung cancer, respectively. ${ }^{24,25} A L O X 5 A P$-rs 4076128 interacts with dietary linoleic acid intake in breast cancer patients, ${ }^{20}$ and $A L O X 5 A P$-rs 4073259 has been detected in patients with ischemic stroke and cerebral infarction. ${ }^{26,27}$ Given the evidence above, we speculated that these SNPs may also be involved in the onset and progression of thyroid cancer. Therefore, we genotyped these SNPs in our thyroid cancer case-control cohort and evaluated the association between the SNPs and the risk of disease.

\section{Materials and Methods}

\section{Subjects}

In total, 520 thyroid cancer cases and 520 healthy controls were collected at Shanxi Provincial People's Hospital. The diagnosis of thyroid cancer was established by histopathological examination of biopsy or resected tissue specimens. All cases were newly diagnosed papillary thyroid carcinoma and previously untreated. The controls were blood donors without a history of cancer, immune disorder or serious disease. All participants provided written informed consent. This study was approved by the Ethics Committee of Shanxi Provincial People's Hospital and carried out in accordance with the World Medical Association Declaration of Helsinki: Ethical Principles for Medical Research Involving Human Subjects.

\section{Genotyping}

Five milliliters of whole blood was collected from each subject in tubes containing ethylenediaminetetraacetic acid. DNA was extracted using a PureLink ${ }^{\mathrm{TM}}$ Pro 96 Genomic DNA Purification Kit (Invitrogen, Carlsbad, CA). Primers were designed using Sequenom MassARRAY Assay Design 3.0 software, and genotypes were detected by Sequenom MassARRAY RS1000 (Sequenom, San Diego, CA).

\section{Statistical Analyses}

Statistical analyses were performed with SPSS package version 20.0 (SPSS, Chicago, IL, USA). Minor allele frequencies (MAFs) in controls were checked for departure from Hardy-Weinberg equilibrium (HWE) in controls. HaploReg v4.1 (https://pubs.broadinstitute.org/mammals/haploreg/haploreg.php) was used to predict the potential functions of the SNPs. The associations between SNPs and thyroid cancer risk were evaluated using SNPstats (https://www.snpstats.net/start. $\underline{\mathrm{htm}}$ ) and are expressed as the odds ratios (ORs) and 95\% confidence intervals (CIs). Statistical significance was established when $p<0.05$. 
Table I The Basic Information of the Participants

\begin{tabular}{|c|c|c|c|c|}
\hline Characteristics & Case $(n=520)$ & Control $(n=520)$ & $\chi^{2} / \mathbf{t}$ & $p$ \\
\hline \multicolumn{5}{|l|}{ Sex (\%) } \\
\hline Male & $166(31.9)$ & 174 (33.5) & \multirow[t]{2}{*}{0.280} & \multirow[t]{2}{*}{0.597} \\
\hline Female & $354(68.1)$ & $346(66.5)$ & & \\
\hline \multicolumn{5}{|l|}{ Age } \\
\hline Mean $\pm S D$ & $49.99 \pm 12.54$ & $49.22 \pm 12.12$ & 0.382 & 0.313 \\
\hline
\end{tabular}

\section{Results}

The basic information of the participants is described in Table 1. The cases included 166 males and 354 females, with a mean age of 49.9 years, and the control group contained 174 males and 346 females, with a mean age of 49.22 years. No significant differences were observed in the distribution of sex or age between the two groups $(p>0.05)$.

The basic information and predicted functions of candidate SNPs are listed in Table 2. The predicted function according to the HaploReg database showed that rs429358 and rs7412 in $A P O E$ were missense variants and led to changed amino acids. In addition, rs34698726 and rs8100239 in BCL3 and rs4076128 and rs4073259 in ALOX5AP were involved in the regulation of the promoter or enhancer histone, DNAse, changed motifs, and eQTL hits.

The MAFs of SNPs in thyroid cancer cases and healthy controls are presented in Table 3. All of the SNPs were consistent with HWE ( $>$ > 0.05). Comparing the MAFs of each SNP between cases and controls, we found that five SNPs had potential effects on thyroid cancer risk: rs429358 and rs7412 in APOE, rs34698726 and rs8100239 in BCL3, and rs4076128 in ALOX5AP. The minor alleles of rs429358, rs34698726 and rs8100239 were associated with an increased risk of thyroid cancer (rs429358: $\mathrm{OR}=1.465,95 \% \mathrm{CI}: 1.170-1.833, p=0.001$; rs34698726: $\mathrm{OR}=1.316,95 \% \mathrm{CI}$ : $1.103-1.569, p=0.002$; rs8100239: OR $=1.410,95 \%$ CI: $1.163-1.709, p<0.001)$. In contrast, the minor alleles of rs7412 and rs4076128 were correlated with a decreased risk of disease (rs7412: OR $=0.585,95 \%$ CI: $0.446-0.767, p<$ 0.001; rs4076128: OR $=0.698,95 \%$ CI: $0.584-0.835, p<0.001$ ).

The genotype frequencies of SNPs in cases and controls are shown in Table 4. Compared with the TT genotype of rs 429358 , the TC genotype exhibited a 1.59-fold increased risk of thyroid cancer $(p=0.002)$. The TA and TT genotypes of rs34698726 were related to a 1.33 -fold and 1.79-fold elevated risk of disease, respectively $(p=0.007)$. Moreover, the AT and AA genotypes of rs 8100239 were associated with a 1.32-fold and 2.09-fold increased risk of disease, respectively $(p=0.002)$. In contrast, the CT and TT genotypes of rs 7412 were found to be protective against the risk of thyroid cancer

Table 2 Basic Information and Predicted Functions of Candidate SNPs

\begin{tabular}{|l|l|l|l|l|l|}
\hline SNP & Gene & Position & Allele & Role & Predicted Functions \\
\hline rs429358 & APOE & chr19:44908684 & T>C & Missense Variant & Cys130Arg \\
\hline rs7412 & APOE & chr19:44908822 & C>T & Missense Variant & Arg176Cys \\
\hline rs34698726 & BCL3 & chr19:44740744 & A >T & $\begin{array}{l}\text { Upstream } \\
\text { Variant }\end{array}$ & Enhancer histone mark, motifs changed, eQTL hits \\
\hline rs8100239 & BCL3 & chr19:44749847 & T>A & Intron Variant & DNAse, motifs changed \\
\hline rs4076128 & ALOX5AP & chr13:30731006 & A>G & Intron Variant & $\begin{array}{l}\text { Promoter/Enhancer histone marks, DNAse, motifs changed, eQTL } \\
\text { hits }\end{array}$ \\
\hline rs4073259 & ALOX5AP & chr13:30732134 & A>G & Intron Variant & $\begin{array}{l}\text { Promoter/Enhancer histone marks, DNAse, motifs changed, eQTL } \\
\text { hits }\end{array}$ \\
\hline
\end{tabular}

Abbreviations: SNP, single nucleotide polymorphism; eQTL, expression quantitative trait locus. 
Table 3 The MAF and HWE of Candidate SNPs in Thyroid Cancer Cases and Healthy Controls

\begin{tabular}{|l|l|l|l|l|l|l|}
\hline SNP & Gene & MAF-Cases & MAF-Controls & HWE $\boldsymbol{p}$ & OR (95\% CI) \\
\hline rs429358 & APOE & 0.21 & 0.15 & 0.99 & $1.465(1.170-1.833)$ & $0.00 I^{*}$ \\
\hline rs7412 & APOE & 0.09 & 0.15 & 0.73 & $0.585(0.446-0.767)$ & $<0.00 I^{*}$ \\
\hline rs34698726 & BCL3 & 0.43 & 0.36 & 0.51 & $1.316(1.103-1.569)$ & $0.002 *$ \\
\hline rs8100239 & BCL3 & 0.32 & 0.25 & 0.64 & $1.410(1.163-1.709)$ & $<0.001 *$ \\
\hline rs4076128 & ALOX5AP & 0.33 & 0.41 & 0.21 & $0.698(0.584-0.835)$ & $<0.001 *$ \\
\hline rs4073259 & ALOX5AP & 0.45 & 0.43 & 0.18 & $1.076(0.906-1.280)$ & 0.402 \\
\hline
\end{tabular}

Note: ${ }^{*} p<0.05$ indicates statistical significance.

Abbreviations: SNP, single nucleotide polymorphism; MAF, minor allele frequency; HWE, Hardy-Weinberg equilibrium.

$(p=0.0003)$, and the GA and GG genotypes of rs4076128 were also associated with a decreased risk of disease $(p=$ $0.0001)$.

The influence of SNPs on the risk of thyroid cancer was further evaluated using three genetic models (Table 5). $A P O E$-rs429358 was correlated with an increased risk of disease under dominant and log-additive models $(p$ dominant $=$ $\left.0.0004, p_{\text {log-additive }}=0.0006\right) . B C L 3$-s34698726 and rs8100239 were associated with an elevated risk of disease under all

Table 4 Genotype Frequency Distributions Between Thyroid Cancer Cases and Healthy Controls

\begin{tabular}{|c|c|c|c|c|c|c|}
\hline SNP & Gene & Genotype & Control & Case & OR $(95 \% \mathrm{CI})$ & $p$ \\
\hline \multirow[t]{3}{*}{ rs429358 } & \multirow[t]{3}{*}{$A P O E$} & TT & 37I (7I.3\%) & 317 (6I\%) & 1 & \multirow[t]{3}{*}{$0.002^{*}$} \\
\hline & & $\mathrm{TC}$ & I 37 (26.4\%) & I 86 (35.8\%) & $1.59(1.22-2.08)$ & \\
\hline & & $\mathrm{CC}$ & 12 (2.3\%) & 17 (3.3\%) & I.68 (0.79-3.57) & \\
\hline \multirow[t]{3}{*}{ rs74I2 } & \multirow[t]{3}{*}{$A P O E$} & $\mathrm{CC}$ & 376 (72.3\%) & 427 (82.1\%) & I & \multirow[t]{3}{*}{$0.0003 *$} \\
\hline & & $\mathrm{CT}$ & I34 (25.8\%) & 90 (I7.3\%) & $0.59(0.43-0.79)$ & \\
\hline & & $\mathrm{TT}$ & 10 (1.9\%) & $3(0.6 \%)$ & $0.26(0.07-0.95)$ & \\
\hline \multirow[t]{3}{*}{ rs34698726 } & \multirow[t]{3}{*}{$B C L 3$} & AA & 208 (40\%) & 166 (31.9\%) & 1 & \multirow[t]{3}{*}{$0.007 *$} \\
\hline & & TA & 248 (47.7\%) & 264 (50.8\%) & $1.33(1.02-1.74)$ & \\
\hline & & TT & 64 (12.3\%) & 90 (I7.3\%) & $1.79(1.22-2.62)$ & \\
\hline \multirow[t]{3}{*}{ rs8100239 } & \multirow[t]{3}{*}{$B C L 3$} & $\mathrm{TT}$ & 297 (57.1\%) & $25 I$ (48.3\%) & I & \multirow[t]{3}{*}{$0.002 *$} \\
\hline & & AT & 189 (36.4\%) & 209 (40.2\%) & $1.32(1.02-1.71)$ & \\
\hline & & AA & 34 (6.5\%) & 60 (II.5\%) & $2.09(1.33-3.28)$ & \\
\hline \multirow[t]{3}{*}{ rs 4076128} & \multirow[t]{3}{*}{ ALOX5AP } & AA & I7I (32.9\%) & 236 (45.4\%) & I & \multirow[t]{3}{*}{$0.000 I^{*}$} \\
\hline & & GA & 267 (5I.4\%) & 224 (43.1\%) & $0.61(0.47-0.79)$ & \\
\hline & & GG & 82 (I5.8\%) & 60 (II.5\%) & $0.53(0.36-0.78)$ & \\
\hline \multirow[t]{3}{*}{ rs4073259 } & \multirow[t]{3}{*}{ ALOX5AP } & AA & 175 (33.6\%) & 158 (30.4\%) & I & \multirow[t]{3}{*}{0.470} \\
\hline & & GA & 240 (46.1\%) & 255 (49\%) & I.19 (0.90-I.57) & \\
\hline & & GG & 105 (20.2\%) & 107 (20.6\%) & $1.13(0.80-1.60)$ & \\
\hline
\end{tabular}

Note: $*_{p}<0.05$ indicates statistical significance.

Abbreviations: SNP, single nucleotide polymorphism; OR, odds ratio; $\mathrm{Cl}$, confidence interval. 
three genetic models $(p<0.05)$. In contrast, $A P O E$-rs 7412 was related to a decreased risk of thyroid cancer under dominant and log-additive models $\left(p_{\text {dominant }}=0.0001, p_{\text {log-additive }}=0.0001\right)$. Moreover, $A L O X 5 A P$-rs 4076128 was also correlated with a reduced risk of disease under all three genetic models $(p<0.05)$.

The morbidity of thyroid cancer in females was higher than that in males. Therefore, stratified analysis was carried out according to sex (Table 6). BCL3-s34698726 was correlated with an elevated risk of thyroid cancer in both males and females $(p<0.05)$. Moreover, $A P O E$-rs 7412 and $A L O X 5 A P$-rs 4076128 were associated with a decreased risk of disease in both males and females $(p<0.05)$. However, $A P O E$-rs429358 and BCL3-rs8100239 were associated with an increased risk of disease only in females. In addition, $A L O X 5 A P$ - rs4073259 was found to be associated with an increased risk of disease $(p=0.006)$.

\section{Discussion}

With in-depth study, ferroptosis has gradually exhibited enormous potential in cancer prevention and treatment. However, few studies have focused on ferroptosis-related gene polymorphisms in thyroid cancer. In this study, we genotyped six SNPs in the ferroptosis-related genes APOE, BCL3 and ALOX5AP and found that rs429358, rs34698726 and rs8100239 were associated with an increased risk of thyroid cancer. In contrast, rs7412 and rs4076128 were related to a decreased risk of disease.

APOE is a polymorphic protein and has multiple functions in the transport and catabolism of triglycerides and cholesterol. It can bind to the receptors of low-density lipoprotein and chylomicron and therefore regulate lipid metabolism. ${ }^{28}$ Based on its function, the abnormal expression and dysregulation of APOE has been widely investigated in earlier studies about the etiology and pathogenesis of diseases related to lipid metabolism, such as atherosclerosis, cerebral infarction and chronic heart disease. ${ }^{29,30}$ More recent studies have gradually revealed the important role of APOE in cell proliferation, tumor angiogenesis, invasion and migration. Dysregulation of APOE has been found in a number of cancers, including glioblastoma, gastric cancer, and thyroid cancer. ${ }^{31-33}$ Rs429358 and rs 7412 are common SNPs in $A P O E$ and lead to changes in the Cys130Arg and Arg176Cys amino acids, respectively. ${ }^{34}$ In this study, we found that rs429358 was a risk variant for thyroid cancer, and rs7412 was a protective variant against the risk of disease, suggesting that rs429358 and rs7412 may participate in the pathogenesis of thyroid cancer by altering the function of APOE in cellular lipid catabolism and ferroptosis.

BCL3 was first identified in chronic lymphocytic leukemia, and subsequent studies found its function as a transcriptional coactivator in the NF- $\mathrm{KB}$ signaling pathway. ${ }^{35}$ Unlike the general $\mathrm{I} \kappa \mathrm{B}$ proteins that directly bind to $\mathrm{NF}-\kappa \mathrm{B}$ proteins and regulate their activity, BCL3 usually binds to $\mathrm{p} 50$ and $\mathrm{p} 52$ homodimers to upregulate or suppress a number of genes in the NF- $\mathrm{KB}$ pathway. ${ }^{36} \mathrm{BCL} 3$ was also identified as a candidate proto-oncogene and plays essential roles in the pathogenesis of tumors. ${ }^{37}$ Park et al reported that hepatitis Bx protein can upregulate the expression of BCL3 and lead to upregulation of the kappaB2 (p52)/BCL3 complex, thereby participating in the progression of hepatocellular carcinoma. ${ }^{38}$ Wakefield et al found that BCL3 can promote the pulmonary metastasis of ErbB2-positive breast cancer by suppressing cell migration, GDP dissociation and metalloprotease inhibitors. ${ }^{17}$ In addition, Chen et al showed that BCL3 can bind to and inhibit the ubiquitination and degradation of Smad3 and therefore promote the metastasis of breast cancer by regulating TGF $\beta$ signaling. ${ }^{39}$ We identified that $B C L 3$-s34698726 and rs8100239 were associated with an elevated risk of thyroid cancer under all three genetic models, suggesting that BCL3 mutations may also contribute to the progression of thyroid cancer. However, the underlying molecular mechanism needs to be explored in further studies.

ALOX5AP can stimulate the enzymatic activity of 5-lipoxygenase and convert arachidonic acid into leukotrienes. Leukotrienes are then hydrolyzed into several products in the 5-lipoxygenase pathway and function as inflammatory mediators in the pathogenesis of allergic diseases and chronic inflammatory conditions. ${ }^{40}$ ALOX5AP was also identified to have essential roles in the occurrence of cancer because of its participation in the 5-lipoxygenase pathway. Jiang et al reported the abnormal expression of ALOX5AP in breast cancer and identified is as closely associated with the prognosis of breast cancer patients, suggesting its potential use as a therapeutic target. ${ }^{41}$ Recently, Ye et al reported that ALOX5AP is upregulated in serous ovarian cancer, and its overexpression is correlated with poor prognosis and survival. ${ }^{42}$ Polymorphisms of ALOX5AP are also associated with a number of other diseases and cancers, including ischemic stroke, cerebral infarction, lung disease, and breast cancer. ${ }^{20,43,44}$ We genotyped two SNPs in ALOX5AP in our case- 
Table 5 Association Between SNPs and Risk of Thyroid Cancer in Genetic Models

\begin{tabular}{|c|c|c|c|c|c|c|c|}
\hline SNP & Gene & Model & Genotype & Control & Case & OR $(95 \% \mathrm{Cl})$ & $p$ \\
\hline \multirow[t]{5}{*}{ rs429358 } & \multirow[t]{5}{*}{ APOE } & \multirow[t]{2}{*}{ Dominant } & $\mathrm{TT}$ & $37 \mid$ (7I.3\%) & $317(61 \%)$ & 1 & \multirow[t]{2}{*}{$0.0004 *$} \\
\hline & & & TC-CC & 149 (28.6\%) & 203 (39\%) & $1.60(1.23-2.07)$ & \\
\hline & & \multirow[t]{2}{*}{ Recessive } & TT-TC & 508 (97.7\%) & 503 (96.7\%) & 1 & \multirow[t]{2}{*}{0.330} \\
\hline & & & $\mathrm{CC}$ & $12(2.3 \%)$ & 17 (3.3\%) & $1.45(0.68-3.06)$ & \\
\hline & & Log-additive & - & - & - & $1.49(1.18-1.88)$ & $0.0006^{*}$ \\
\hline \multirow[t]{5}{*}{ rs74I2 } & \multirow[t]{5}{*}{ APOE } & \multirow[t]{2}{*}{ Dominant } & $\mathrm{CC}$ & 376 (72.3\%) & 427 (82.1\%) & I & \multirow[t]{2}{*}{$0.000 I^{*}$} \\
\hline & & & CT-TT & I 44 (27.7\%) & 93 (I7.9\%) & $0.56(0.42-0.76)$ & \\
\hline & & \multirow[t]{2}{*}{ Recessive } & CC-CT & $510(98.1 \%)$ & 517 (99.4\%) & 1 & \multirow[t]{2}{*}{0.051} \\
\hline & & & TT & 10 (1.9\%) & $3(0.6 \%)$ & $0.29(0.08-1.06)$ & \\
\hline & & Log-additive & - & - & - & $0.57(0.43-0.75)$ & $0.0001 *$ \\
\hline \multirow[t]{5}{*}{ rs34698726 } & \multirow[t]{5}{*}{$B C L 3$} & \multirow[t]{2}{*}{ Dominant } & AA & 208 (40\%) & 166 (31.9\%) & I & \multirow[t]{2}{*}{$0.0066^{*}$} \\
\hline & & & TA-TT & $312(60 \%)$ & 354 (68.1\%) & $1.42(1.10-1.84)$ & \\
\hline & & \multirow[t]{2}{*}{ Recessive } & AA-TA & 456 (87.7\%) & 430 (82.7\%) & I & \multirow[t]{2}{*}{$0.018^{*}$} \\
\hline & & & TT & 64 (12.3\%) & 90 (I7.3\%) & $1.52(1.07-2.15)$ & \\
\hline & & Log-additive & - & - & - & $1.34(1.11-1.60)$ & $0.0016^{*}$ \\
\hline \multirow[t]{5}{*}{ rs8100239 } & \multirow[t]{5}{*}{$B C L 3$} & \multirow[t]{2}{*}{ Dominant } & TT & 297 (57.1\%) & $25 I(48.3 \%)$ & I & \multirow[t]{2}{*}{$0.0037^{*}$} \\
\hline & & & AT-AA & 223 (42.9\%) & 269 (5I.7\%) & $1.44(1.12-1.84)$ & \\
\hline & & \multirow[t]{2}{*}{ Recessive } & TT-AT & 486 (93.5\%) & 460 (88.5\%) & 1 & \multirow[t]{2}{*}{$0.0049 *$} \\
\hline & & & $A A$ & 34 (6.5\%) & 60 (II.5\%) & $1.86(1.20-2.89)$ & \\
\hline & & Log-additive & - & - & - & $1.39(1.15-1.68)$ & $0.0006^{*}$ \\
\hline \multirow[t]{5}{*}{ rs4076I 28} & \multirow[t]{5}{*}{ ALOX5AP } & \multirow[t]{2}{*}{ Dominant } & AA & I7I (32.9\%) & 236 (45.4\%) & I & \multirow[t]{2}{*}{$<\left.0.000\right|^{*}$} \\
\hline & & & GA-GG & 349 (67.1\%) & 284 (54.6\%) & $0.59(0.46-0.76)$ & \\
\hline & & \multirow[t]{2}{*}{ Recessive } & AA-GA & 438 (84.2\%) & 460 (88.5\%) & I & \multirow[t]{2}{*}{$0.043^{*}$} \\
\hline & & & GG & 82 (I5.8\%) & 60 (II.5\%) & $0.69(0.48-0.99)$ & \\
\hline & & Log-additive & - & - & - & $0.69(0.58-0.83)$ & $0.0001 *$ \\
\hline rs4073259 & ALOX5AP & Dominant & AA & 175 (33.6\%) & I 58 (30.4\%) & I & 0.23 \\
\hline & & & GA-GG & 345 (66.3\%) & 362 (69.6\%) & I.I7 (0.90-I.52) & \\
\hline & & Recessive & AA-GA & 415 (79.8\%) & $4 \mid 3$ (79.4\%) & I & 0.89 \\
\hline & & & GG & 105 (20.2\%) & 107 (20.6\%) & I.02 (0.76-I.38) & \\
\hline & & Log-additive & - & - & - & $1.08(0.9|-| .28)$ & 0.39 \\
\hline
\end{tabular}

Note: $* p<0.05$ indicates statistical significance.

Abbreviations: SNP, single nucleotide polymorphism; OR, odds ratio; $\mathrm{Cl}$, confidence interval. 
Table 6 Association Between Candidate SNPs and Risk of Thyroid Cancer Stratified by Sex

\begin{tabular}{|c|c|c|c|c|c|c|c|}
\hline \multirow[t]{2}{*}{ SNP } & \multirow[t]{2}{*}{ Gene } & \multirow[t]{2}{*}{ Model } & \multirow[t]{2}{*}{ Genotype } & \multicolumn{2}{|c|}{ Male } & \multicolumn{2}{|c|}{ Female } \\
\hline & & & & OR $(95 \% \mathrm{CI})$ & $p$ & OR $(95 \% \mathrm{Cl})$ & $p$ \\
\hline \multirow[t]{5}{*}{ rs429358 } & \multirow[t]{5}{*}{$A P O E$} & \multirow[t]{2}{*}{ Dominant } & TT & 1.00 & \multirow[t]{2}{*}{0.920} & 1.00 & \multirow[t]{2}{*}{$<0.000 I^{*}$} \\
\hline & & & TC-CC & $0.98(0.61-1.56)$ & & $2.00(I .46-2.75)$ & \\
\hline & & \multirow[t]{2}{*}{ Recessive } & TT-TC & 1.00 & \multirow[t]{2}{*}{0.950} & 1.00 & \multirow[t]{2}{*}{0.240} \\
\hline & & & $\mathrm{CC}$ & $1.05(0.26-4.28)$ & & $1.69(0.69-4.16)$ & \\
\hline & & Log-additive & - & $0.99(0.65-1.49)$ & 0.950 & I.8I (I.37-2.4I) & $<0.000 I^{*}$ \\
\hline \multirow[t]{5}{*}{ rs7412 } & \multirow[t]{5}{*}{ APOE } & \multirow[t]{2}{*}{ Dominant } & $\mathrm{CC}$ & 1.00 & \multirow[t]{2}{*}{$0.010 *$} & 1.00 & \multirow[t]{2}{*}{$0.004 *$} \\
\hline & & & CT-TT & $0.49(0.28-0.85)$ & & $0.60(0.42-0.85)$ & \\
\hline & & \multirow[t]{2}{*}{ Recessive } & CC-CT & 1.00 & \multirow[t]{2}{*}{0.110} & 1.00 & \multirow[t]{2}{*}{0.210} \\
\hline & & & TT & $0.22(0.02-1.89)$ & & $0.37(0.07-1.91)$ & \\
\hline & & Log-additive & - & $0.50(0.30-0.83)$ & $0.006 *$ & $0.61(0.43-0.85)$ & $0.003 *$ \\
\hline \multirow[t]{5}{*}{ rs34698726 } & \multirow[t]{5}{*}{$B C L 3$} & \multirow[t]{2}{*}{ Dominant } & AA & 1.00 & \multirow[t]{2}{*}{0.050} & 1.00 & \multirow[t]{2}{*}{$0.035^{*}$} \\
\hline & & & TA-TT & $1.57(1.00-2.47)$ & & $1.40(1.02-1.90)$ & \\
\hline & & \multirow[t]{2}{*}{ Recessive } & AA-TA & 1.00 & \multirow[t]{2}{*}{$0.046^{*}$} & 1.00 & 0.170 \\
\hline & & & TT & $1.84(1.00-3.38)$ & & $1.34(0.88-2.06)$ & \\
\hline & & Log-additive & - & $1.47(1.07-2.02)$ & $0.016 *$ & $1.28(1.03-1.60)$ & $0.028^{*}$ \\
\hline rs8100239 & $B C L 3$ & Dominant & TT & 1.00 & 0.260 & 1.00 & $0.008^{*}$ \\
\hline & & & AT-AA & $1.28(0.83-1.98)$ & & $1.49(1.11-2.01)$ & \\
\hline & & Recessive & TT-AT & 1.00 & 0.360 & 1.00 & $0.004^{*}$ \\
\hline & & & AA & $1.40(0.68-2.86)$ & & $2.24(1.27-3.94)$ & \\
\hline & & Log-additive & - & $1.23(0.89-1.69)$ & 0.210 & I.48 (I.17-I.87) & $0.001 *$ \\
\hline rs 4076128 & ALOX5AP & Dominant & AA & 1.00 & $0.034^{*}$ & 1.00 & $0.0008^{*}$ \\
\hline & & & GA-GG & $0.62(0.40-0.97)$ & & $0.59(0.43-0.80)$ & \\
\hline & & Recessive & AA-GA & 1.00 & $0.006 *$ & 1.00 & 0.530 \\
\hline & & & GG & $0.38(0.18-0.78)$ & & $0.87(0.57-1.33)$ & \\
\hline & & Log-additive & - & $0.61(0.44-0.86)$ & $0.004^{*}$ & $0.74(0.60-0.92)$ & $0.007^{*}$ \\
\hline rs4073259 & ALOX5AP & Dominant & AA & 1.00 & 0.006 & 1.00 & 0.700 \\
\hline & & & GA-GG & $1.96(1.20-3.18)$ & & $0.94(0.69-1.29)$ & \\
\hline & & Recessive & AA-GA & 1.00 & 0.800 & 1.00 & 0.980 \\
\hline & & & GG & I.07 (0.64-I.79) & & $0.99(0.68-1.45)$ & \\
\hline & & Log-additive & - & $1.34(0.99-1.82)$ & 0.059 & $0.97(0.79-1.19)$ & 0.780 \\
\hline
\end{tabular}

Note: $*_{p}<0.05$ indicates statistical significance.

Abbreviations: SNP, single nucleotide polymorphism; OR, odds ratio; $\mathrm{Cl}$, confidence interval. 
control cohort and found that $A L O X 5 A P$-rs4076128 was also correlated with a reduced risk of thyroid cancer. The results provide new clues for functional studies on ALOX5AP in thyroid cancer.

Considering the high incidence rate of thyroid cancer in females, we performed a stratification analysis. The results showed that $A P O E$-rs7412, BCL3-s34698726 and $A L O X 5 A P$-rs4076128 remained significant in both males and females, while $A P O E$-rs429358 and $B C L 3$-rs8100239 were associated with the risk of disease only in females. We suppose that $A P O E$-rs429358 and BCL3-rs8100239 may interact with hormonal regulation in female patients with thyroid cancer, and the relatively small sample size of males may have influenced the different results.

Several limitations of this study need to be highlighted. Although we performed a stratification analysis based on sex, the interaction between candidate SNPs and other factors, such as tumor size and presence or absence of metastasis, could not be evaluated due to the limited information. However, the results identified here could not represent the comprehensive genetic background and driver role of the APOE, BCL3 and ALOX5AP genes in patients with thyroid cancer because only seven candidate SNPs were genotyped in this Chinese population. The underlying molecular mechanism between $A P O E, B C L 3$ and $A L O X 5 A P$ and thyroid cancer needs to be explored in further functional studies.

In conclusion, the present study found that $A P O E$-rs429358, BCL3-s34698726 and rs8100239 were associated with an elevated risk of thyroid cancer, while $A P O E$-rs 7412 and $A L O X 5 A P$-rs4076128 were related to a reduced risk of disease. The results help us better understand how genetic polymorphisms in ferroptosis-related genes are relevant to thyroid cancer susceptibility.

\section{Disclosure}

The authors report no conflicts of interest in this work.

\section{References}

1. Bray F, Ferlay J, Soerjomataram I, Siegel RL, Torre LA, Jemal A. Global cancer statistics 2018: GLOBOCAN estimates of incidence and mortality worldwide for 36 cancers in 185 countries. CA Cancer J Clin. 2018;68(6):394-424. doi:10.3322/caac.21492

2. Deng Y, Li H, Wang M, et al. Global burden of thyroid cancer from 1990 to 2017. JAMA Netw Open. 2020;3(6):e208759. doi:10.1001/ jamanetworkopen.2020.8759

3. Chmielik E, Rusinek D, Oczko-Wojciechowska M, et al. Heterogeneity of thyroid cancer. Pathobiology. 2018;85(1-2):117-129.

4. Laha D, Nilubol N, Boufraqech M. New therapies for advanced thyroid cancer. Front Endocrinol. 2020;11:82. doi:10.3389/fendo.2020.00082

5. Kitahara CM, Preston DL, Neta G, et al. Occupational radiation exposure and thyroid cancer incidence in a cohort of U.S. radiologic technologists, 1983-2013. Int J Cancer. 2018;143(9):2145-2149. doi:10.1002/ijc.31270

6. Myung SK, Lee CW, Lee J, Kim J, Kim HS. Risk factors for thyroid cancer: a hospital-based case-control study in Korean adults. Cancer Res Treat. 2017;49(1):70-78. doi:10.4143/crt.2015.310

7. Prete A, Borges de Souza P, Censi S, Muzza M, Nucci N, Sponziello M. Update on fundamental mechanisms of thyroid cancer. Front Endocrinol. 2020;11:102. doi:10.3389/fendo.2020.00102

8. Liu R, Xing M. TERT promoter mutations in thyroid cancer. Endocr Relat Cancer. 2016;23(3):R143-155. doi:10.1530/ERC-15-0533

9. Khan MS, Qadri Q, Makhdoomi MJ, et al. RET/PTC gene rearrangements in thyroid carcinogenesis: assessment and clinico-pathological correlations. Pathol Oncol Res. 2020;26(1):507-513. doi:10.1007/s12253-018-0540-3

10. Mou Y, Wang J, Wu J, et al. Ferroptosis, a new form of cell death: opportunities and challenges in cancer. J Hematol Oncol. 2019;12(1):34. doi:10.1186/s13045-019-0720-y

11. Wang Y, Wei Z, Pan K, Li J, Chen Q. The function and mechanism of ferroptosis in cancer. Apoptosis. 2020;25(11-12):786-798. doi:10.1007/ s10495-020-01638-w

12. Lin R, Fogarty CE, Ma B, et al. Identification of ferroptosis genes in immune infiltration and prognosis in thyroid papillary carcinoma using network analysis. BMC Genomics. 2021;22(1):576. doi:10.1186/s12864-021-07895-6

13. Ostendorf BN, Bilanovic J, Adaku N, et al. Common germline variants of the human APOE gene modulate melanoma progression and survival. Nat Med. 2020;26(7):1048-1053. doi:10.1038/s41591-020-0879-3

14. Chang NW, Chen DR, Wu CT, et al. Influences of apolipoprotein E polymorphism on the risk for breast cancer and HER2/neu status in Taiwan. Breast Cancer Res Treat. 2005;90(3):257-261. doi:10.1007/s10549-004-4656-7

15. Zhao Z, Zou S, Guan X, et al. Apolipoprotein E overexpression is associated with tumor progression and poor survival in colorectal cancer. Front Genet. 2018;9:650. doi:10.3389/fgene.2018.00650

16. Schuster M, Annemann M, Plaza-Sirvent C, Schmitz I. Atypical IкB proteins - nuclear modulators of NF-кB signaling. Cell Commun Signal. 2013;11(1):23. doi:10.1186/1478-811X-11-23

17. Wakefield A, Soukupova J, Montagne A, et al. Bcl3 selectively promotes metastasis of ERBB2-driven mammary tumors. Cancer Res. 2013;73 (2):745-755. doi:10.1158/0008-5472.CAN-12-1321

18. Ahlqvist K, Saamarthy K, Syed Khaja AS, Bjartell A, Massoumi R. Expression of Id proteins is regulated by the Bcl-3 proto-oncogene in prostate cancer. Oncogene. 2013;32(12):1601-1608. doi:10.1038/onc.2012.175

19. Puvvada SD, Funkhouser WK, Greene K, et al. NF-kB and Bcl-3 activation are prognostic in metastatic colorectal cancer. Oncology. 2010;78(34):181-188. doi:10.1159/000313697 
20. Wang J, John EM, Ingles SA. 5-lipoxygenase and 5-lipoxygenase-activating protein gene polymorphisms, dietary linoleic acid, and risk for breast cancer. Cancer Epidemiol Biomarkers Prev. 2008;17(10):2748-2754. doi:10.1158/1055-9965.EPI-08-0439

21. Saadat M. Apolipoprotein E (APOE) polymorphisms and susceptibility to breast cancer: a meta-analysis. Cancer Res Treat. 2012;44(2):121-126. doi:10.4143/crt.2012.44.2.121

22. Kato I, Land S, Barnholtz-Sloan J, Severson RK. APOE and FABP2 polymorphisms and history of myocardial infarction, stroke, diabetes, and gallbladder disease. Cholesterol. 2011;2011:896360. doi:10.1155/2011/896360

23. Galal AA, Abd Elmajeed AA, Elbaz RA, Wafa AM, Elshazli RM. Association of Apolipoprotein E gene polymorphism with the risk of T2DM and obesity among Egyptian subjects. Gene. 2021;769:145223. doi:10.1016/j.gene.2020.145223

24. Hong CC, Sucheston-Campbell LE, Liu S, et al. Genetic variants in immune-related pathways and breast cancer risk in african american women in the AMBER consortium. Cancer Epidemiol Biomarkers Prev. 2018;27(3):321-330. doi:10.1158/1055-9965.EPI-17-0434

25. Dimitrakopoulos FI, Antonacopoulou AG, Kottorou A, et al. Variant of BCL3 gene is strongly associated with five-year survival of non-small-cell lung cancer patients. Lung Cancer. 2015;89(3):311-319. doi:10.1016/j.lungcan.2015.06.006

26. Zhang R, Guo X, Li X, et al. Arachidonate 5-lipoxygenase-activating protein (ALOX5AP) gene rs4073259 polymorphism not associated with ischemic stroke in the northeastern Chinese Han population. Clin Neurol Neurosurg. 2014;119:64-69. doi:10.1016/j.clineuro.2014.01.004

27. Zhang SY, Xu ML, Zhang CE, et al. Association of ALOX5AP gene single nucleotide polymorphisms and cerebral infarction in the Han population of northern China. BMC Med Genet. 2012;13:61. doi:10.1186/1471-2350-13-61

28. Gliemann J. Receptors of the low density lipoprotein (LDL) receptor family in man. Multiple functions of the large family members via interaction with complex ligands. Biol Chem. 1998;379(8-9):951-964.

29. Hofman A, Ott A, Breteler MM, et al. Atherosclerosis, apolipoprotein E, and prevalence of dementia and alzheimer's disease in the Rotterdam study. Lancet. 1997;349(9046):151-154. doi:10.1016/S0140-6736(96)09328-2

30. Wilson PW, Schaefer EJ, Larson MG, Ordovas JM. Apolipoprotein E alleles and risk of coronary disease. A meta-analysis. Arterioscler Thromb Vasc Biol. 1996;16(10):1250-1255. doi:10.1161/01.ATV.16.10.1250

31. Nicoll JA, Zunarelli E, Rampling R, Murray LS, Papanastassiou V, Stewart J. Involvement of apolipoprotein E in glioblastoma: immunohistochemistry and clinical outcome. Neuroreport. 2003;14(15):1923-1926.

32. Oue N, Hamai Y, Mitani Y, et al. Gene expression profile of gastric carcinoma: identification of genes and tags potentially involved in invasion, metastasis, and carcinogenesis by serial analysis of gene expression. Cancer Res. 2004;64(7):2397-2405. doi:10.1158/0008-5472.CAN-03-3514

33. Ito Y, Takano T, Miyauchi A. Apolipoprotein e expression in anaplastic thyroid carcinoma. Oncology. 2006;71(5-6):388-393. doi:10.1159/ 000107112

34. Seripa D, D'Onofrio G, Panza F, Cascavilla L, Masullo C, Pilotto A. The genetics of the human APOE polymorphism. Rejuvenation Res. 2011;14 (5):491-500. doi:10.1089/rej.2011.1169

35. Hatada EN, Nieters A, Wulczyn FG, et al. The ankyrin repeat domains of the NF-kappa B precursor p105 and the protooncogene bcl-3 act as specific inhibitors of NF-kappa B DNA binding. Proc Natl Acad Sci U S A. 1992;89(6):2489-2493. doi:10.1073/pnas.89.6.2489

36. Legge DN, Chambers AC, Parker CT, Timms P, Collard TJ, Williams AC. The role of B-Cell Lymphoma-3 (BCL-3) in enabling the hallmarks of cancer: implications for the treatment of colorectal carcinogenesis. Carcinogenesis. 2020;41(3):249-256. doi:10.1093/carcin/bgaa003

37. Maldonado V, Melendez-Zajgla J. Role of Bcl-3 in solid tumors. Mol Cancer. 2011;10:152. doi:10.1186/1476-4598-10-152

38. Park SG, Chung C, Kang H, Kim JY, Jung G. Up-regulation of cyclin D1 by HBx is mediated by NF-kappaB2/BCL3 complex through kappaB site of cyclin D1 promoter. J Biol Chem. 2006;281(42):31770-31777. doi:10.1016/S0021-9258(19)84092-9

39. Chen X, Cao X, Sun X, et al. Bcl-3 regulates TGF $\beta$ signaling by stabilizing Smad3 during breast cancer pulmonary metastasis. Cell Death Dis. 2016;7(12):e2508. doi:10.1038/cddis.2016.405

40. Rubin P, Mollison KW. Pharmacotherapy of diseases mediated by 5-lipoxygenase pathway eicosanoids. Prostaglandins Other Lipid Mediat. 2007;83(3):188-197. doi:10.1016/j.prostaglandins.2007.01.005

41. Jiang WG, Douglas-Jones AG, Mansel RE. Aberrant expression of 5-lipoxygenase-activating protein (5-LOXAP) has prognostic and survival significance in patients with breast cancer. Prostaglandins Leukot Essent Fatty Acids. 2006;74(2):125-134. doi:10.1016/j.plefa.2005.10.005

42. Ye X, An L, Wang X, et al. ALOX5AP predicts poor prognosis by enhancing M2 macrophages polarization and immunosuppression in serous ovarian cancer microenvironment. Front Oncol. 2021;11:675104. doi:10.3389/fonc.2021.675104

43. Shi Y, Xu L, Feng Q, et al. Allele-specific methylation contributed by CpG-SNP is associated with regulation of ALOX5AP gene expression in ischemic stroke. Neurol Sci. 2018;39(10):1717-1724. doi:10.1007/s10072-018-3489-9

44. Kowal-Bielecka O, Chwiesko-Minarowska S, Bernatowicz PL, et al. The arachidonate 5-lipoxygenase activating protein gene polymorphism is associated with the risk of scleroderma-related interstitial lung disease: a multicentre European scleroderma trials and research group (EUSTAR) study. Rheumatology. 2017;56(5):844-852. doi:10.1093/rheumatology/kew499

Pharmacogenomics and Personalized Medicine

Dovepress

\section{Publish your work in this journal}

Pharmacogenomics and Personalized Medicine is an international, peer-reviewed, open access journal characterizing the influence of genotype on pharmacology leading to the development of personalized treatment programs and individualized drug selection for improved safety, efficacy and sustainability. This journal is indexed on the American Chemical Society's Chemical Abstracts Service (CAS). The manuscript management system is completely online and includes a very quick and fair peer-review system, which is all easy to use. Visit http://www. dovepress.com/testimonials.php to read real quotes from published authors.

Submit your manuscript here: https://www.dovepress.com/pharmacogenomics-and-personalized-medicine-journal 